\title{
Perfil de ácidos graxos de cadeia longa e qualidade da carne de novilhos terminados em confinamento com diferentes níveis de monensina sódica na dieta
}

\author{
Long Chain Fatty acids profile and meat quality of feedlot finished steers with different levels \\ of sodium monensin at the diet
}

\author{
Luís Fernando Glasenapp de Menezes ${ }^{1}$ Gilberto Vilmar Kozloski ${ }^{2}$ João Restle ${ }^{3}$ \\ Francisco Carlos Deschamps ${ }^{4}$ Ivan Luiz Brondani ${ }^{5}$ Angélica Pereira dos Santos ${ }^{2}$ \\ Jarlei Fiamoncini ${ }^{6}$
}

\section{RESUMO}

Foi avaliada a composição química e a qualidade da carne de 48 novilhos das raças Charolês, Nelore e suas cruzas, terminados em confinamento, recebendo à vontade uma dieta com $52 \%$ de silagem de milho e $48 \%$ de concentrado, adicionada com 0, 100 ou 200mg/dia de monensina sódica, em um delineamento inteiramente casualizado. A dieta apresentou $12,3 \%$ de proteína bruta e $58,3 \%$ de fibra em detergente neutro. A monensina foi fornecida misturada com o concentrado. A adição da monensina não alterou o teor de matéria seca, de proteína bruta e de extrato etéreo do músculo Longissimus dorsi dos animais $(P>0,05)$, assim como não influenciou a perda de líquidos durante o descongelamento ou à cocção, a força de cisalhamento, a maciez, a cor e o marmoreio $(P>0,05)$. No entanto, a palatabilidade e suculência diminuíram linearmente com a inclusão de monensina na dieta $(P<0,05)$. A textura da carne, por sua vez, variou de forma quadrática com o aumento da inclusão de monensina $(P<0,05)$. A inclusão do ionóforo não influenciou a proporção de ácidos graxos de cadeia longa saturados em relação aos insaturados $(P>0,05)$, mas aumentou linearmente o teor dos isômeros cis e trans do oleato (C18:1 $n 9 c$ e C18:1 n9t). Embora tenha aumentado o teor destes ácidos graxos insaturados específicos, a adição da monensina diminuiu a qualidade da carne dos animais, principalmente por palatabilidade e à suculência.

Palavras-chave: ácidos graxos de cadeia longa, bovinos de corte, ionóforos, qualidade da carne.

\section{ABSTRACT}

The chemical composition and meat quality of 48 feedlot finished Charolais-Nellore steers, fed ad libitum with a

\begin{abstract}
$52 \%$ corn silage and $48 \%$ concentrate, diet that included 0 , 100 or $200 \mathrm{mg} /$ day of sodium monensin, were evaluated in a completely randomized design. Diets contained $12.3 \%$ of crude protein and $58.3 \%$ of neutral detergent fibre. Monensin was mixed with the concentrate. Monensin addition did not alter the Longissimus dorsi muscle content of dry matter, crude protein and ether extract $(P>0.05)$, nor influenced meat thawing or cooking losses, shear force, tenderness, color and marbling $(P>0.05)$. However, the palatability and juiciness decreased linearly with monensin addition $(P<0.05)$. On the other hand, meat texture varied in a quadratic way as monensin level increased $(P<0,05)$. Ionophore inclusion did not influence saturated to unsaturated fatty acids ratio $(P>0.05)$, but increased linearly the content of oleate cis and trans isomers (C18:1 n9c e C18:1 n9t). Although the proportion of these specific fatty acids increased, monensin addition reduced meat quality, mainly by decreasing palatability and juiciness.
\end{abstract}

Key words: saturated fatty acids, unsaturated fatty acids, ionophore, palatability, juiciness.

\section{INTRODUÇÃO}

O Brasil produz anualmente em torno de 8 milhões de toneladas de carne bovina, o que representa cerca de $16 \%$ da produção mundial total. No entanto, exporta apenas 1,2 milhões de toneladas, o que representa apenas $15 \%$ do total produzido no país (ANUALPEC, 2004). Entre os aspectos limitantes ao aumento deste número, estão as barreiras impostas

${ }^{1}$ Programa de Pós-graduação em Zootecnia (PPGZ), Universidade Federal de Santa Maria (UFSM), Santa Maria, RS, Brasil. Rua 2, n³5, apto 204, Parque Monte Carlo, Bairro Camobi, Santa Maria. CEP:97110-000. E-mail: 1fgdm@yahoo.com.br. Autor para correspondência

${ }^{2}$ PPGZ, UFSM, Santa Maria, RS, Brasil.

${ }^{3}$ Universidade Federal de Goiás, (UFG), Goiânia, GO, Brasil.

${ }^{4}$ Empresa de Pesquisa Agropecuária e Extensão Rural (EPAGRI), Itajaí, SC, Brasil.

${ }_{5}^{5}$ Departamento de Zootecnia, UFSM, Santa Maria, RS, Brasil.

${ }^{6}$ Curso de Biotecnologia, Universidade do Vale do Itajaí (UNIVALI), Itajaí, SC, Brasil. 
pelos mercados importadores, principalmente no aspecto sanitário, e a difusão de informações e conceitos associando o consumo de carne vermelha a problemas para a saúde humana, particularmente cardiovasculares. Entretanto, tem sido amplamente demonstrado que diferentes ácidos graxos poliinsaturados de cadeia longa participam de vários processos metabólicos benéficos à saúde humana (COOK et al., 2001; VARELA et al., 2004) e que as gorduras de ruminantes são fontes naturais de alguns deles (FRENCH et al., 2000).

Outro aspecto que, muitas vezes, limita a comercialização internacional da carne é o uso de aditivos químicos nas dietas dos animais. Entre eles, os antibióticos ionóforos tem sido os mais amplamente utilizados, particularmente em sistemas confinados de produção. A monensina sódica é um ionóforo que, dependendo da dose, altera o padrão da fermentação ruminal, aumentando a produção de propionato e diminuindo a produção de metano e amônia. Além disso aumenta o fluxo de proteína não degradada no rúmen para o intestino delgado. Como resultado, em geral, há um aumento na eficiência do uso do alimento pelo animal e menor risco de ocorrer acidose ruminal (THOMAS, 1998). A monensina parece também alterar a atividade microbiana ruminal sobre os lipídios da dieta. Estudos in vitro têm demonstrado que as taxas de hidrólise dos triglicerídios e de biohidrogenação dos ácidos graxos foram reduzidas na presença de monensina(VANNEVEL\& DEMEYER, 1995; FELLNER et al., 1997) e EIFERT (2004), por sua vez, verificou que a proporção de ácidos graxos insaturados do leite foi mais alto em vacas recebendo dietas com monensina. No entanto, não foram encontradas na literatura, publicações em que tenha sido avaliado o efeito da monensina sobre o perfil de ácidos graxos de cadeia longa depositados na carcaça e, somente alguns poucos estudos, relacionaram a presença da monensina na dieta com características qualitativas da carne. GOODRICH et al. (1984) revisaram dados de literatura e concluíram que o grau de marmorização da carne tende a diminuir com o aumento dos níveis de monensina na dieta dos animais. Da mesma forma, ZINN \& BORQUES (1993) e OSCAR et al. (1987) observaram que o marmoreio da carne de animais que receberam dietas com monensina foi menor que naqueles que consumiram dietas sem o aditivo. No entanto, RESTLE et al. (2000a,b) e CLARY et al. (1993) não observaram efeito da monensina sobre o grau de marmoreio e nem sobre outras características qualitativas da carne de vacas e novilhas terminadas em confinamento. Estas diferenças de resultados podem estar associadas a diferenças genéticas dos animais, de dietas ou, de outra forma, às quantidades de ionóforo fornecido aos animais.

Deste modo, este estudo foi conduzido para avaliar se a presença de monensina sódica na dieta poderia alterar o perfil de ácidos graxos de cadeia longa, e as características sensoriais e organolépticas da carne de novilhos terminados em confinamento.

\section{MATERIAL E MÉTODOS}

O experimento foi realizado no setor de bovinocultura de corte da Universidade Federal de Santa Maria. Foram utilizados 48 novilhos das raças Charolês, Nelore e suas cruzas, terminados em confinamento, em um delineamento experimental inteiramente casualizado, recebendo dietas sem (T0), ou com 100 (T100) ou 200 mg de monensina sódica/ animal/ dia (T200). Os animais permaneceram 97 dias confinados recebendo alimentação à vontade, com $52 \%$ de silagem de milho e $48 \%$ de concentrado, composto por farelo de trigo, uréia e minerais. A dieta total apresentou $12,32 \%$ de proteína bruta e $58,30 \%$ de fibra em detergente neutro, sendo que a monensina foi fornecida misturada ao concentrado.

Os animais foram abatidos em frigorífico comercial após jejum de sólidos de 14 horas. As carcaças foram mantidas em câmara fria, à temperatura de $0^{\circ} \mathrm{C}$, durante 24 horas e então submetidas às avaliações. Na meia carcaça direita, foi feito um corte entre a $12^{\mathrm{a}}$ e $13^{\mathrm{a}}$ costelas, com o objetivo de expor o músculo Longissimus dorsi para sua extração. Neste músculo, foram avaliadas a coloração e a textura, seguindo escala de 1 a 5 pontos, na qual: 1 = coloração escura e textura muito grosseira e $5=$ coloração vermelha brilhante e textura muito fina, assim como o marmoreio, seguindo uma escala numérica correspondente à classificação em: traços, leve, pequeno, médio, moderado e abundante (MÜLLER, 1987). Para avaliação de maciez, palatabilidade, suculência e força de cisalhamento das fibras musculares, foi retirada uma amostra do músculo Longissimus dorsi, entre a $10^{\mathrm{a}}$ e $12^{\mathrm{a}}$ costelas, que foi embalada em lâmina de plástico e papel pardo e imediatamente congelada, à temperatura de $-18^{\circ} \mathrm{C}$, por 15 dias. Após este período, foram retirados quatro bifes, de $2,5 \mathrm{~cm}$ de espessura, da porção cranial da amostra, ainda congelada, e colocados para descongelar em refrigerador doméstico, à temperatura de $4^{\circ} \mathrm{C}$, por 24 horas. Após descongelados, duas fatias foram assadas a uma temperatura interna de $70^{\circ} \mathrm{C}$. Um dos bifes era pesado congelado e novamente quando descongelado, para cálculo da quebra no descongelamento e, após a cocção, para cálculo da quebra na cocção. Nestas 
mesmas amostras de bife, foi avaliada também a força necessária ao cisalhamento das fibras musculares, efetuando-se três leituras por bife no aparelho WarnerBratzler Shear. O segundo bife foi destinado à avaliação de maciez, palatabilidade e suculência por meio de um painel composto de quatro avaliadores treinados. Foram atribuídos valores subjetivos de 1 a 9, onde 1 correspondia à carne extremamente dura, gosto extremamente desagradável e extremamente seca, 5 à carne com maciez, palatabilidade e suculência médias e, 9, à carne extremamente macia, saborosa e suculenta.

A terceira amostra dos bifes foi seca em estufa de ventilação forçada $\left(55^{\circ} \mathrm{C}\right)$, moídas (peneira de $1 \mathrm{~mm})$ e armazenadas para posterior análise. Nestas amostras, foi feita a extração dos lipídios utilizando-se um método modificado de FOLCH et al. (1957). Cerca de $0,5 \mathrm{~g}$ de amostra foi colocada em um tubo de vidro e adicionado $10 \mathrm{ml}$ de uma mistura de clorofórmio/metanol (2:1). Após 24 horas, foi adicionado $10 \mathrm{ml}$ de água destilada e os tubos foram centrifugados a $500 \times$ g por 5 minutos para separar as fases. Transferiu-se a fase orgânica (clorofórmio) para tubos de ensaio com tampa rosqueável, sendo deixada em banho-maria a $40^{\circ} \mathrm{C} \mathrm{sob}$ fluxo de ar comprimido, até restarem apenas os lipídios no fundo do tubo. Para derivatização e metilação dos ácidos graxos, foram adicionados no tubo com os lipídios 500ml de $\mathrm{KOH} \mathrm{0,4M} \mathrm{em} \mathrm{metanol,} \mathrm{deixando-se}$ em banho-maria a $60^{\circ} \mathrm{C}$ por 2 horas. Após, os tubos foram deixados esfriar à temperatura ambiente e então adicionado $1,5 \mathrm{~mL}$ de $\mathrm{H}_{2} \mathrm{SO}_{4} 1 \mathrm{M} \mathrm{em}$ metanol. Os tubos foram deixados novamente em banho-maria a $60^{\circ} \mathrm{C}$ por mais 2 horas. A seguir, foram resfriados e adicionados $2 \mathrm{ml}$ de n-hexano para recuperar os derivados (ésteres metílicos dos ácidos graxos), transferindo-se o conteúdo para frascos adequados para posterior análise. A determinação foi feita em cromatógrafo a gás, equipado com detector de ionização de chama e coluna capilar Supelco SP2340 (60m x 0,25mm x 0,2 $\mu \mathrm{m})$. As temperaturas do detector e injetor foram $260^{\circ} \mathrm{C} \mathrm{e} 240^{\circ} \mathrm{C}$, respectivamente. A programação de aquecimento da coluna foi iniciada com $140^{\circ} \mathrm{C}$ por 5 minutos e aumento gradual de $4^{\circ} \mathrm{C}$ por minuto até a temperatura final de $240^{\circ} \mathrm{C}$, permanecendo assim por $5 \mathrm{~min}$. O fluxo de gás de arraste (H2) foi de $17 \mathrm{ml} / \mathrm{min}$. O volume de injeção foi de $0,5 \mu \mathrm{L}$ com razão de split de 1:100. A identificação dos picos, assim como a quantificação, foi feita pela comparação dos tempos de retenção e da área dos picos das amostras com as de padrões de ésteres metílicos de ácidos graxos (Supelco 37 components FAMEs Mix, ref. 47885-U).

Os dados foram submetidos à análise de regressão, sendo os graus de liberdade do modelo separados nos efeitos linear e quadrático. A espessura de gordura subcutânea foi considerada como covariável. As análises foram realizadas utilizando-se o programa estatístico SAS (1997).

\section{RESULTADOS E DISCUSSÃO}

A inclusão de monensina não influenciou $(\mathrm{P}>0,05)$ os teores de matéria seca, proteína bruta e extrato etéreo (Tabela 1), assim como não influenciou $(\mathrm{P}>0,05)$ a quebra ao descongelamento e à cocção, e a força de cisalhamento da carne dos novilhos (tabela $2)$. No entanto, diminuiu linearmente $(\mathrm{P}<0,05)$ a palatabilidade e a suculência da carne. Para cada mg de monensina adicionada na dieta, a pontuação referente a estas carcaterísticas diminuiu 0,008 e 0,023 pontos, respectivamente, independente da variação na espessura da gordura subcutânea. A explicação para este efeito não é clara. Poderia estar associada à presença residual do aditivo na carne. No entanto, uma vez que isto não foi analisado, esta hipótese é somente especulativa. O consumo de monensina pelos animais não afetou a cor e o marmoreio ( $\mathrm{P}>0,05)$, mas influenciou quadraticamente $(\mathrm{P}<0,05)$ a textura da carne (Tabela 2$)$, sendo as piores texturas observadas pela adição da quantidade intermediária de monensina.

Em geral os resultados obtidos, neste estudo, diferem de vários outros, em que também foi avaliado o efeito da monensina sobre a qualidade da carne de bovinos (GOODRICH et al.,1984; OSCAR et al., 1987; CLARY et al.,1993; ZINN \& BORQUES, 1993; RESTLE et al., 2000a,b). Isto indica que outros fatores, como o tipo genético do animal e a dieta, entre outros, interagem com a monensina para exercer efeitos sobre as características qualitativas da carne dos bovinos.

Os resultados do perfil de ácidos graxos de cadeia longa do músculo Longissimus dorsi dos novilhos são apresentados na tabela 3. Com exceção dos ácidos heptadecanóico e oléico, a adição de

Tabela 1 - Composição química (\%) da carne de novilhos terminados em confinamento recebendo diferentes níveis de monensina sódica na dieta

\begin{tabular}{llllll}
\hline \multirow{2}{*}{ Características } & \multicolumn{2}{l}{ Nível de monensina sódica, mg/dia } & & \\
\cline { 2 - 4 } & 0 & 100 & 200 & & \\
\cline { 2 - 5 } & 0 & 26,1 & 26,1 & 0,3 & $\mathrm{~ns}$ \\
\hline Matéria seca & 26,3 & 20,7 & 21,0 & 0,2 & $\mathrm{~ns}$ \\
Proteína bruta & 20,8 & 2,0 & 2,1 & 0,2 & $\mathrm{~ns}$ \\
Extrato etéreo & 2,2 & 2,0 & & \\
\hline
\end{tabular}

\footnotetext{
${ }^{1}$ Erro padrão das médias em que $\mathrm{n}=16$ por tratamento.

${ }^{2}$ Probabilidade (erro Tipo I): $\mathrm{L}=$ efeito linear, $\mathrm{P}<0,05$; ns= não significativo.
} 
Tabela 2 -Quebra ao descongelamento (QDESC) e à cocção (QCOC), força de cisalhamento (WBS) e características qualitativas da carne de novilhos terminados em confinamento, recebendo diferentes níveis de monensina sódica na dieta.

\begin{tabular}{llllll}
\hline \multirow{2}{*}{ Características } & \multicolumn{3}{l}{ Nível de monensina, mg/dia } & & \\
\cline { 2 - 4 } & 0 & 100 & 200 & & $\mathrm{PP}^{1}$ \\
& & & & \\
\hline QDESC, \% & 14,8 & 13,5 & 19,5 & 2,7 & $\mathrm{~ns}$ \\
QCOC, \% & 21,8 & 22,0 & 23,9 & 1,0 & $\mathrm{~ns}$ \\
WBS, kgF & 3,7 & 4,1 & 3,9 & 0,2 & $\mathrm{~ns}$ \\
Maciez $^{3}$ & 7,1 & 7,0 & 7,0 & 0,2 & $\mathrm{~ns}$ \\
Palatabilidade $^{3}$ & 7,8 & 6,8 & 6,3 & 0,2 & $\mathrm{~L}$ \\
Suculência $^{3}$ & 7,5 & 6,6 & 6,0 & 0,3 & $\mathrm{~L}$ \\
Cor $^{4}$ & 4,13 & 4,08 & 4,11 & 0,2 & $\mathrm{~ns}$ \\
Textura $^{5}$ & 4,56 & 3,28 & 4,12 & 0,2 & $\mathrm{Q}$ \\
Marmoreio $^{6}$ & 5,74 & 5,11 & 6,84 & 0,7 & $\mathrm{~ns}$ \\
\hline
\end{tabular}

${ }^{1}$ Erro padrão das médias que $\mathrm{n}=16$ por tratamento.

${ }^{2}$ Probabilidade (erro Tipo I): $\mathrm{L}=$ efeito linear, $\mathrm{P}<0,05 ; \mathrm{Q}=$ efeito quadrático, $(\mathrm{P}<0,05)$ e ns = não significativo.

${ }_{3}^{3}$ Pontuação de 1 a 9 , sendo: 1 = sem suculência, sem sabor, extremamente dura; 9 = extremamente suculenta, extremamente saborosa e extremamente macia.

${ }^{4}$ Pontuação de 1 a 5 , sendo 1 = escura, 3 = vermelha levemente escura, $5=$ vermelha viva.

${ }^{5}$ Pontuação de 1 a 5 , sendo 1 = muito grosseira, 5 = muito fina;

${ }^{6}$ Pontuação de 1 a 18 , sendo: 1 a $3=\operatorname{traços;~} 4$ a $6=$ leve; 7 a $9=$ pequeno; 10 a $12=$ médio; 13 a $15=$ grande; 16 a $18=$ abundante

monensina não influenciou o teor da maioria dos ácidos graxos de cadeia longa da carne, e nem a proporção entre saturados e insaturados ou entre poli e monoinsaturados $(\mathrm{P}>0,05)$. Os ácidos palmítico, esteárico e o oléico representaram em torno de $90 \%$ dos ácidos graxos analisados e, de outro modo, a forma trans do oléico representou somente em torno de $0,5 \%$ do teor total deste ácido.

O teor de ácido heptadecanóico (C17:0) variou quadraticamente $(\mathrm{P}<0,05)$ com o aumento da inclusão de monensina na dieta, sendo observado o menor valor no nível intermediário de inclusão do aditivo. EIFERT (2004) analisou o perfil de ácidos graxos da gordura do leite de vacas da raça Holandês, recebendo ou não monensina na dieta, e também observou aumento na concentração do ácido C17:0 com a inclusão do aditivo. Isto provavelmente está associado ao efeito da monensina sobre a atividade microbiana ruminal, uma vez que ácidos graxos de cadeia ímpar, como o C17:0, são sintetizados pelas bactérias com a utilização de propionato e valerato e estão presentes nos lipídios microbianos (MANSBRIDGE \& BLAKE, 1997). Os resultados do presente estudo indicam, no entanto, que este efeito é dose-dependente.

O teor do isômero trans do oléico (C18:1 n9t) aumentou e, do isômero cis (C18:1 n9t), diminuiu linearmente $(\mathrm{P}<0,05)$ com o aumento do ionóforo na dieta. Da mesma forma, DESCHAMPS et al. (2004) observaram que a inclusão de monensina na dieta também reduziu o teor de oleato da carne de vacas de descarte terminadas em confinamento. A forma trans do oleato origina-se durante o processo de biohidrogenação dos ácidos graxos insaturados pelas bactérias ruminais (MANSBRIDGE \& BLAKE, 1997)e, em estudos com vacas em lactação, foi verificado que o teor deste ácido graxo no leite foi mais alto em animais recebendo ionóforo (CANT et al., 1997; SAUER et al., 1998).

A quantidade total, assim como a composição dos ácidos graxos consumidos pela população, tem recebido atenção crescente por órgãos públicos de saúde, principalmente nos países desenvolvidos. O Departamento de Saúde do Reino Unido, por exemplo, recomenda que o consumo de gordura não deve ultrapassar $30 \%$ do consumo energético total e, desta, mais da metade deve ser representada por ácidos graxos insaturados. Além disso, a relação entre ácidos graxos polinsaturados e saturados deveria ser acima de 40\% (WOOD et al.,

Tabela 3 - Perfil ${ }^{1}$ dos ácidos graxos de cadeia longa da carne de novilhos terminados em confinamento, recebendo diferentes níveis de monensina sódica na dieta

\begin{tabular}{|c|c|c|c|c|c|}
\hline \multirow{2}{*}{ Ácido graxo ${ }^{2}$} & \multicolumn{3}{|c|}{ Nível de monensina, mg } & \multirow{2}{*}{$\mathrm{EP}^{3}$} & \multirow{2}{*}{$\mathrm{P}^{4}$} \\
\hline & 0 & 100 & 200 & & \\
\hline C14:0 & 2,5 & 2,7 & 2,6 & 0,1 & $\mathrm{~ns}$ \\
\hline C14:1 & 0,38 & 0,40 & 0,25 & 0,08 & ns \\
\hline $\mathrm{C} 15: 0$ & 0,07 & 0,03 & 0,04 & 0,02 & ns \\
\hline $\mathrm{C} 16: 0$ & 27,7 & 28,1 & 28,6 & 0,4 & $\mathrm{~ns}$ \\
\hline C16:1 & 3,1 & 3,4 & 3,2 & 0,1 & $\mathrm{~ns}$ \\
\hline $\mathrm{C} 17: 0$ & 0,80 & 0,76 & 0,85 & 0,02 & Q \\
\hline $\mathrm{C} 17: 1$ & 0,41 & 0,30 & 0,23 & 0,07 & ns \\
\hline C18:0 & 19,2 & 18,93 & 19,6 & 0,6 & ns \\
\hline $\mathrm{C} 18: 1 \mathrm{n} 9 \mathrm{t}$ & 0,22 & 0,30 & 0,50 & 0,1 & $\mathrm{~L}$ \\
\hline $\mathrm{C} 18: 1 \mathrm{n} 9 \mathrm{c}$ & 43,0 & 42,2 & 41,1 & 0,6 & $\mathrm{~L}$ \\
\hline $\mathrm{C} 18: 2 \mathrm{n} 6 \mathrm{c}$ & 2,2 & 2,5 & 2,4 & 0,1 & ns \\
\hline $\mathrm{C} 20: 4 \mathrm{n} 6$ & 0,41 & 0,39 & 0,41 & 0,08 & $\mathrm{~ns}$ \\
\hline Saturados & 50,2 & 50,5 & 51,7 & 0,6 & $\mathrm{~ns}$ \\
\hline Insaturados & 49,8 & 49,4 & 48,3 & 0,7 & $\mathrm{~ns}$ \\
\hline Monoinsaturados & 47,1 & 46,6 & 45,3 & 0,7 & ns \\
\hline Polinsaturados & 2,6 & 2,9 & 2,8 & 0,2 & ns \\
\hline
\end{tabular}

${ }^{1}$ Proporção em relação à quantidade total de ácidos graxos

${ }^{2}$ C14:0 = Ácido Mirístico; C14:1 = Ácido Miristoléico; C15:0 = Ácido Pentadecanóico; C16:0 = Ácido Palmítico; C16:1 = Ácido Palmitoléico; C17:0 = Ácido Heptadecanóico; C17:1 = Ácido cis10-Heptadecanóico; C18:0 = Ácido Esteárico; C18:1n9t = Ácido Elaídico; $\mathrm{C} 18: 1 \mathrm{n} 9 \mathrm{c}=$ Ácido Oléico; $\mathrm{C} 18: 2 \mathrm{n} 6 \mathrm{c}=$ Ácido Linoléico; C20:4n6 = Ácido Araquidônico.

${ }^{3}$ Erro padrão das médias onde $\mathrm{n}=16$ por tratamento.

${ }^{4}$ Probabilidade (erro Tipo I): $\mathrm{L}=$ efeito linear, $\mathrm{Q}=$ efeito quadrático, $\mathrm{P}<0,05 ;$ ns= não significativo. 
2003). No entanto, no presente estudo, o teor de polinsaturados representou em média somente em torno de $5 \%$ dos ácidos graxos saturados totais e, assim como no estudo conduzido por DESCHAMPS et al. (2004), a monensina não influenciou a proporção dos ácidos graxos saturados e insaturados (em torno de 50\%), e nem a proporção entre mono e polinsaturados presentes na carne. De outra forma, a inclusão de ionóforo na dieta de vacas lactantes inclusive diminuiu a proporção dos ácidos graxos insaturados do leite (EIFERT, 2004). Estes resultados indicam que muitos estudos ainda são necessários visando melhorar o perfil dos ácidos graxos de cadeia longa depositados na carne dos bovinos, mas que não incluem o uso de ionóforos.

\section{CONCLUSÕES}

A adição de monensina na dieta não modificou a maioria dos ácidos graxos de cadeia longa estudados, mas diminuiu a palatabilidade e a suculência da carne de novilhos terminados em confinamento. Houve diminuição do teor de ácido oléico e aumento na presença de ácido elaídico à medida que aumentou a presença de monensina na dieta.

\section{AGRADECIMENTOS}

À Coordenação de Aperfeiçoamento de Pessoal de Nível Superior (CAPES), pela bolsa concedida a Menezes.

Ao Programa de Apoios a Projetos Institucionais com a Participação de Recém Doutores (PRODOC), pela bolsa concedida à Kozloski.

Ao Conselho Nacional de Desenvolvimento Científico e Tecnológico (CNPq), pelas bolsas de Produtividade concedidas a Restle e Brondani.

Ao CNPq pela Bolsa concedida a Santos.

\section{REFERÊNCIAS}

ANUALPEC. Anuário estatístico da produção animal. FNP. São Paulo: Camargo Soares, 2004. 359p.

CANT, J.P. et al. Effect of fish oil on milk composition in dairy cows. Canadian Journal of Animal Science, v.77, p.125-131, 1997.

CLARY, E.M. et al. Supplemental fat and ionophores in finishing diets: feedlot performance and ruminal digesta kinetics in steers. Journal of Animal Science, v.71, p.3115-3123, 1993.

COOK, M.E. et al. CLA inhibitis the induction of prostaglandin and leukotriene synthesis. A natural substitute for non-steroidal anti-inflammatory drugs. In: INTERNACIONAL CONFERENCE ON CLA, 2001, Alesund. Proceedings... Alesund: NATURAL ASA, 2001, p.6-7.

DESCHAMPS, F.C. et al. Avaliação do perfil dos ácidos graxos de cadeia longa na carcaça de vacas de descarte recebendo dietas com ou sem monensina. In: REUNIÃO ANUAL DA SOCIEDADE BRASILEIRA DE ZOOTECNIA, 40., Campo Grande, 2004. Anais... Campo Grande: SBZ, 2004. CD ROM.

EIFERT, E.C. Fontes de carboidratos, óleo de soja e monensina para vacas lactantes: Desempenho, digestibilidade, parâmetros ruminais e perfil de ácidos graxos do leite. 2004. 117f. Tese (Doutorado em Zootecnia) - Universidade Federal de Viçosa.
FELLNER, V. et al. Effect of nigericin, monensin, and tetronasin on biohydrogenation in continuous flow-trough ruminal fermentors. Journal of Dairy Science, v.78, p.1815$1823,1997$.

FOLCH, J. et al. A simple method for the isolation and purification of total lipids from animal tissue. Journal Biological Chemical, v. 226, p.497-509, 1957.

FRENCH, P. et al. Fatt acid composition, including conjugated linoleic acid, of intramuscular fat from steers offered grazed grass, grass silage, or concentrate-based diets. Journal Animal Science, v.78, p.2849-2855, 2000.

GOODRICH, R.D. et al. Influence of monensin on the performance of cattle. Journal of Animal Science, v. 58 , n.6, p.1484-1494, 1984

MANSBRIDGE, R.J.; BLAKE, J.S. Nutritional factors affecting the fatty acid composition of bovine milk. British Journal of Nutrition, v.78, suppl.1, p.S37-S47, 1997.

MÜLlER, L. Normas para avaliação de carcaças e concurso de carcaça de novilhos. 2:ed Santa Maria: UFSM, 1987. $31 \mathrm{p}$.

OSCAR, T.P. et al. Performance, methanogenesis and nitrogen metabolism of finishing steers fed monensin and nickel. Journal of Animal Science, v.64, p.887-896, 1987.

RESTLE, J. et al. Efeito da monensina sódica na composição física e nas características qualitativas da carcaça e da carne de novilhas. In: REUNIÂO ANUAL DA SOCIEDADE BRASILEIRA DE ZOOTECNIA, 37., 2000, Viçosa. Anais... Viçosa: SBZ/Gmosis, 2000a. CD ROM.

RESTLE, J. et al. Efeito da monensina sódica sobre a composição física e as características qualitativas da carcaça e da carne de vacas de descarte. In: REUNIÃO ANUAL DA SOCIEDADE BRASILEIRA DE ZOOTECNIA, 37., 2000, Viçosa. Anais... Viçosa: SBZ/Gmosis, 2000b. CD ROM.

SAS, Institute. SAS'S user's guide. Carry: SAS Institute, 1997. 46p.

SAUER, F.D. et al. Methane output and lactation response in Holstein cattle with monensin or unsaturated fat added to the diet. Journal of Animal Science, v.76, p.906-914, 1998.

THOMAS, E.E. Pontos críticos da utilização de ionóforos em sistemas de cria. In SIMPÓSIO INTERNACIONAL SOBRE PRODUÇ̃̃O INTENSIVA DE GADO DE CORTE, 2., São Paulo, 1998. Anais... São Paulo: FEALQ, 1998. p.32-35.

VAN NEVEL, C.J.; DEMEYER, D.I. Lipólysis and biohidrogenation of soybean oil in the rumen in vitro: Inhibition by antimicrobials. Journal of Dairy Science, v.78, p.27972806, 1995.

VARELA, A. et al. Effect of pasture finishing on the meat characteristics and intramuscular fatty acid profile of steers of the Rubia Gallega breed. Meat Science, v.67, p.515-522, 2004.

WOOD, J.D. et al. Effects of fatty acids on meat quality: a review. Meat Science, v.66, p.21-32, 2003.

ZINN, R.A.; BORQUES, J.L. Influence of sodium bicarbonate and monensin in utilization of a fat-supllemented, high-energy growing-finishing diet by feedlot steers. Journal of Animal Science, v.71, n.1, p.18-25, 1993. 